\title{
КЛИНИЧЕСКАЯ И ДИАГНОСТИЧЕСКАЯ ХАРАКТЕРИСТИКА ПОРАЖЕНИЯ ЦЕНТРАЛЬНОЙ НЕРВНОЙ СИСТЕМЫ У НЕДОНОШЕННЫХ ДЕТЕЙ
}

\author{
Асадова T.A.* \\ Азербайджанский Государственный Институт Усовершенствования врачей им. А.Алиева, \\ кафедра педиатрии, Баку, Азербайджан
}

В данной статье показаны клинические особенности течения гипоксически-ишемической энцефалопатии (ГИЭ) у недо-
ношенных детей в зависимости от гестационного возраста. Показано, что наиболее сильно страдает мозг и легкие, что
способствует развитию неврологических и соматических расстройств. Проведенные исследования показали, что клини-
ческое течение ГИЭ у недоношенных детей находится в прямой зависимости от состояния здоровья матерей, фетопла-
центарного фона, от структурной и фунццональной незрелости мозга младенцев, наличием анте-, интра- и постна-
тальных факторов. Чем меньше гестационный возраст ребенка, тем тяжелее отдаленные последствия со стороны цент-
ральной нервной системы. Наиболее тяжелое течение ГИЭ отмечены у детей с экстремально низкой массой тела
(ЭНМТ) и низкой массой тела (НМТ).

Ключевые слова: недоношенность, патология центральной нервной системы, перинатальная гипоксическая энцефалопатия.

П оражения центральной нервной системы (ЦНС) у недоношенных детей занимают одно из первых мест среди причин ранней заболеваемости, инвалидности и смертности, что связано с высокой частотой встречаемости, разнообразием клинических проявлений и синдромов [1-15]. В структуре детской инвалидности, поражения ЦНС колеблется в интервале от $50 \%$ до $80 \%$ случаев. При тяжелом течении гипоксически-ишемической энцефалопатии (ГИЭ) летальность достигает 25-50\% случаев, большинство которых происходят в первую неделю жизни недоношенных детей и в основном связаны с полиорганной недостаточностью. Преждевременное рождение ребенка продолжает оставаться важной медикосоциальной проблемой современного общества, на долю которого приходится $12 \%$ от всех живорожденных [18]. Несмотря на улучшение профилактических и терапевтических мероприятий в этой области, во всем мире каждый год из 500000 преждевременных родов $75 \%$ приходится на долю 34-36 недель беременности, 25\% $<34$ недель гестационного срока [17-20]. Тяжелые последствия связаны как с состоянием здоровья матерей, наличием перинатальных факторов, так и с тяжестью течения ГИЭ, гестационного возраста младенца. На наш взгляд, чем меньше гестационный возраст ребенка, тем тяжелее отдаленные последствия. Согласно данным ВОЗ, ГИЭ является одной из 10 причин развития инвалидности во всех возрастных группах и занимает 5-ое место в возрасте до 5-ти лет. До $80 \%$ младенцев, после перенесенной тяжелой ГИЭ, впоследствии страдают серьезными неврологическими осложнениями. Несомненно, на сегодняшний день актуальным продолжает оставаться вопрос выявления клинико-диагностических особенностей ГИЭ у недоношенных детей, что и послужило целью для проведения данного научного исследования, который позволит отразить тяжесть повреждений нервной системы у данной категории младенцев в зависимости от гестационного возраста.

Материал и методы исследования. Обследованы 102 недоношенных детей с перинатальным поражением (ПП) ЦНС от матерей с отягощенным акушерским анамнезом в возрасте от 1-го дня до 1-го мес. жизни. Диагноз ПП ЦНС базировался на данных антенатального анамнеза, клинического симптомокомплекса болезни в первые 2-3 недели жизни ребенка, выявлении патогномоничных симптомов поражения ЦНС. Оценка состояния детей проведена по шкале Апгар и Сильвермана. Анализ анамнестических данных показал, что большинство детей родились от матерей в возрасте до 35 лет - 72 (70,6\%), остальные были старше 35 лет - 30 $(29,4 \%)$. Недоношенные дети мужского пола 53 (52\%), женского пола - 49 (48\%); жители города $-70(68,7 \%)$, села $-32(31,3 \%)$. Обследование недоношенных детей проводили в 1-3, 5-7 сутки, повторно на 10-14 сутки. Для решения поставленной цели были использованы следую-

*e-mail: tarana.asadova.67@mail.ru 
щие методы исследований: клинические (постанатальная оценка гестационного возраста (шкала Dubowits L., шкала Дементьевой Г.M. и Коротковой Е.В.), параметры морфофункциональной незрелости по шкале Hoepffnes W., Rauntenbach M., анализировались температурная кривая, антропометрические показатели, функциональное состояние органов и систем. Гестационный возраст младенцев определялся на основании анамнеза матерей, результатов УЗИ, проведенного во время беременности и подтвержденного на основании шкалы Балларда. Степень тяжести неонатальной энцефалопатии определяли на основании результатов оценки по шкале Sarnat H.В. в течение первых 24 часов жизни младенца. Проведены общепринятые рутинные лабораторные и инструментальные методы исследования. Всем детям проводился мониторинг (ЧСС, ЧД, АД, $\mathrm{SpO} 2, \mathrm{pCO} 2$ ), определялся почасовой и суточный диурез, проводилась оценка неврологического статуса. Исследования включали гематологические (гемограмма, гемостаз), биохимические тесты (газы крови, $\mathrm{Na}, \mathrm{K}, \mathrm{Ca}, \mathrm{Mg}$, белок, альбумин, глюкоза, CRP). Помимо этого проводились и инструментальные методы исследования: RHдиагностика органов грудной клетки, НСГ (аппарат "Microl Mabes" фирмы "Ausonic", Австралия); допплерографические исследования сосудистой системы (аппарат "ALOKA SSD1700", с микроконвесным датчиком с частотой 5 мГц и конвесным датчиком с частотой 3,5 мГц); ЭхоКГ, ЭКГ (электрокардиограф "ЭКІК-01"; ЭхоКГ исследования проводились с помощью аппарата "Medikor FTS-21"). Недоношенные дети были осмотрены узкими специалистами: невропатологом, окулистом, кардиологом, отоларингологом, хирургом. Матери были осмотрены терапевтом. Статистическая обработка проводилась с помощью пакета программ "STATISTICA-6", графики строились с помощью "ORIGN-7".

Результаты и обсуждения. Нами проведено комплексное обследование 102 недоношенных детей с гипоксически-ишемической энцефалопатией. В исследование были вовлечены 56 недоношенных детей с ГИЭ и гестационным возрастом 35-37 недель, которые составили I группу и 46 младенцев с ГИЭ, гестационным возрастом от $<28$ до 34 недель, составившие IIю группу (рис. 1). В анамнезе у матерей среди экстрагенитальной патологии отмечены: анемия (железодефицитная) 18,6\% случаев; вирусные инфекции $14,7 \%$; инфекции мочеполовых органов $10,8 \%$; артериальная гипертония $14,7 \%$; нефропатия 4,9\%; эндокринные заболевания (сахарный диабет, заболевания щитовидной железы) 4,9\% случаев соответственно. Среди гинекологических заболеваний отмечены: дисфункция яичников $10,8 \%$ случаев; кольпит $12,7 \%$; эрозия шейки матки 7,8\%; эндометрит $2,9 \%$; эндометриоз яичников $2,9 \%$ случаев. Среди отягощающих факторов наиболее чаще встречались: гестозы 45\% случаев; фетоплацентарная недостаточность $28,4 \%$; угроза прерывания беременности $13,7 \%$; преэклампсия $10,8 \%$ случаев соответственно. Сравнительный анализ общей характеристики младенцев показал: в Iой группе масса тела колебалась в интервале $2112,5 \pm 362,5$ г., тогда как во II-ой группе составило - 1207,5 $\pm 292,5$ г. Оценка состояния по шкале Апгар на 1 мин. в І-ой группе зарегистрировано 4,37 $\pm 0,06$ баллов, на 5-ой мин. $-6,04 \pm 0,1$ тогда как во II-ой группе: на 1-ой мин. отмечено $3,58 \pm 0,07$; на 5-ой мин. 5,45 $\pm 0,07$ баллов соответственно. На СРАР-е находились 14 (25\%) младенцев І-ой группы и 13 (28,2\%) младенцев II-ой группы соответственно. На искусственной вентиляции легких (ИВЛ) находились 8 (4,3\%) детей в I-ой и $9(19,6 \%)$ детей во II-ой группах. Полное парентеральное питание (ПП) получали $12(21,4 \%)$ и $16(34,8 \%)$ в I-ой и во II-ой группах соответственно.

У всех обследованных недоношенных детей отмечены признаки морфофункциональной незрелости. Состояние младенцев в неонатальном периоде характеризовалось поражением различных органов и систем, причем у каждого недоношенного ребенка отмечались по 2-3 патологических синдрома. Характерным для всех наблюдаемых детей было гипоксически-ишемическое поражение (ГИ) ЦНС в 102 (100\%) случаев с различными синдромами: гипертензионный синдром - 24 (23,5\%); судорожный синдром - 31 (30,4\%); гидроцефальный синдром - 5 $(4,9 \%)$; внутричерепные кровоизлияния (ВЧК) I- 


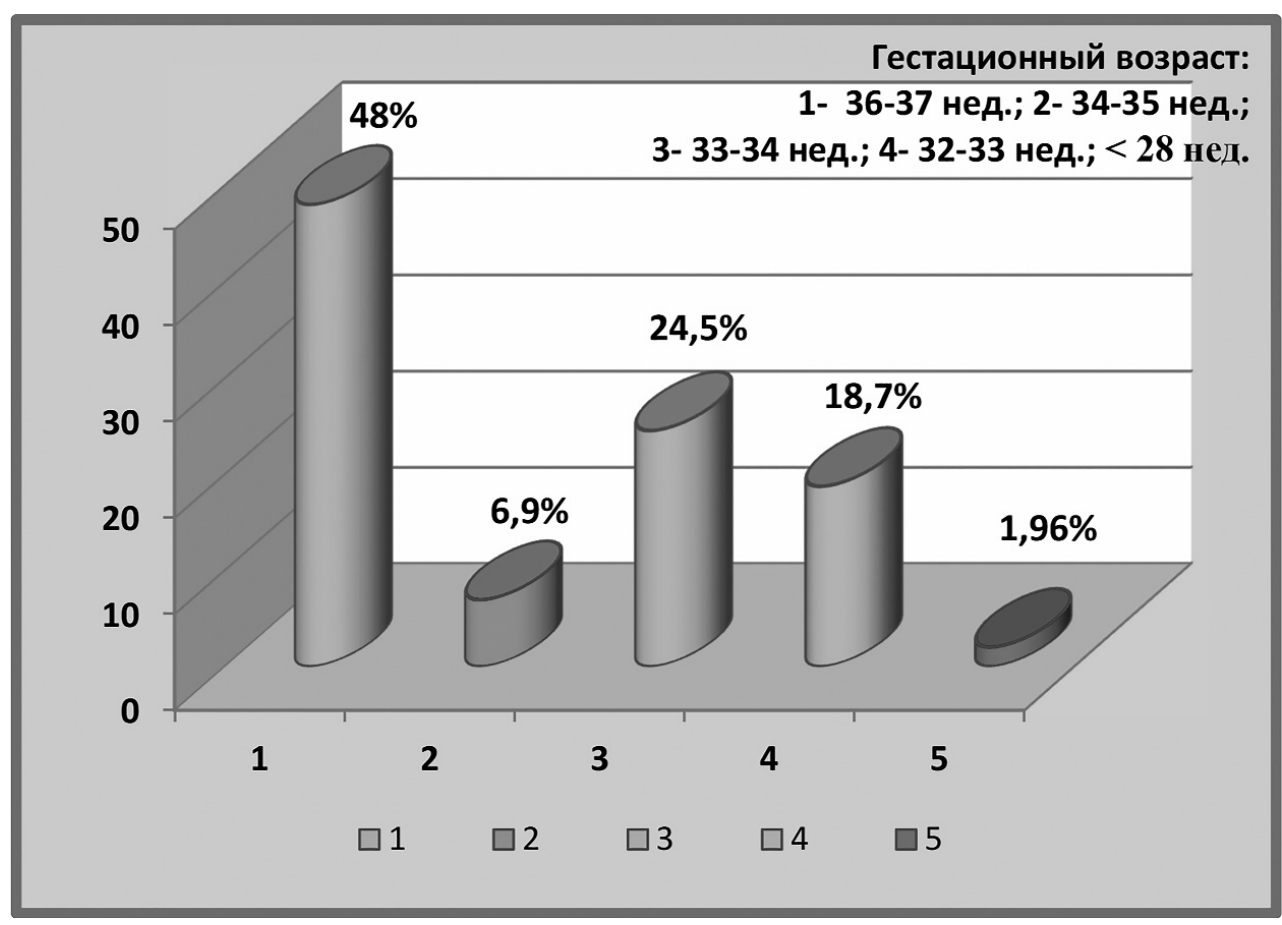

Рис. 1. Диаграмма распределения младенцев в зависимости от гестационного возраста.

IV степени - 38 (37,2\%) случаев; перивентрикулярная лейкомаляция (ПВЛ) - 5 (4,9\%) случаев соответственно. На рис. 2 дана диаграмма частоты встречаемости клинических синдромом и проявлений у обследованных младенцев. Клиническими особенностями проявления поражения ЦНС у недоношенных детей явились: бес- покойство (28,2\%) случаев; гиперстезия (11,2\%); синдром угнетения $(53,4 \%)$; тремор рук и подбородка $(33,7 \%)$; клонус стоп $(8,3 \%)$; изменения мышечного тонуса: дистония $(38,2 \%)$; гипертонус $(13,5 \%)$; гипотония $(11,2 \%)$ и рефлексов: спонтанный рефлексы Моро, Бабинского (67\%) случаев (усилены - 48,3\%; нестойкие - 19,2\%;

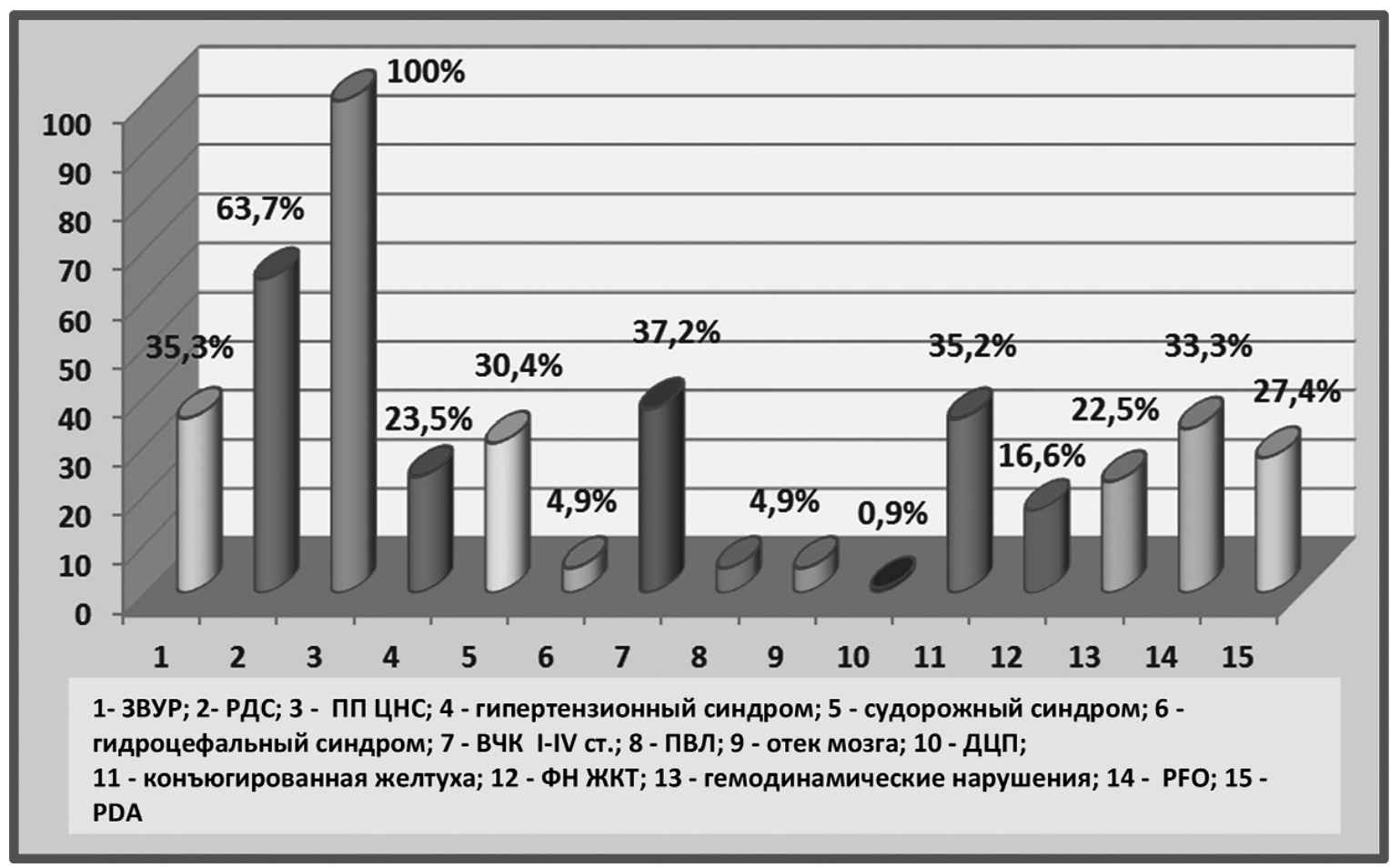

Рис. 2. Диаграмма частоты встречаемости клинических синдромов и проявлений у недоношенных детей. 
ослабленные рефлексы орального автоматизма (POA) - 34\%); выраженная глазная симптоматика (экзофтальм - 37,2\%); положительный симптом "Грефе" - 19\%; преходящее косоглазие $8,6 \%$, горизонтальный нистагм - 7,9\% случаев соответственно.

Гидроцефальные проявления: увеличение окружности головы на 1-2 см. по сравнению с нормой - 15,2\%, расхождение швов, чаще саггитального более чем на 0,5 см - 8,2\% случаев; выбухание и пульсация большого родничка $39,2 \%$ случаев. Также в клинической картине отмечены: адинамия, угнетение сознания, болезненный монотонный крик, клонические судороги.

Проведенные нейросонографические исследования (НСГ) головного мозга у младенцев выявили усиленную пульсацию мозговых сосудов, симметричную дилатацию боковых желудочков, повышенную эхогенность перивентрикулярной области, расширение боковых желудочков, на уровне фронтальных тел у 16 детей, на уровне тел - у 3-х младенцев. ВЧК I-IV степени в перивентрикулярной, интравентрикулярной области. Необходимо отметить, что неврологическая симптоматика у недоношенных детей отмечалась с первых дней жизни. При поражении ЦНС, согласно проведенным допплерографическим исследованиям, у младенцев с гидроцефалией выявлено существенное повышение индекса резистентности сосудов. Так, скорость кровотока по мозговым сосудам (артериям) была повышена, а минимальная - снижена. Это можно объяснить тем, что вентрикулярная дилатация ведет к растяжению артерий и уменьшению их просвета. У недоношенных детей с ВЧК отмечалось замедление кровотока по передней мозговой артерии, в показатели индекса резистентности были повышены. У 14 $(13,7 \%)$ младенцев с постгипоксической энцефалопатией и гемисиндромом наблюдалось ускорение максимальной линейной скорости кровотока на пораженной стороне.

Поражение органов дыхания протекало в виде респираторного дистресс-синдрома (РДС), подтвержденная RH обследованием органов грудной клетки и наблюдалось с первых дней жизни. Отдельно проанализировали состояние здоровья недоношенных детей, родившихся с
ЭНMТ (ELBW - extremely low birth weight) и HMT (SGA - small for qestational age). В результате исследования выявлено, что РДС отмечалось в $63,7 \%$ случаев у наблюдаемых младенцев. Клиническая картина РДС проявлялась симптомами дыхательной недостаточности различной степени тяжести. В 100\% случаев у недоношенных детей с ЭНМТ и НМТ отмечалось температурная нестабильность (гипотермия), что свидетельствовало о незрелости терморегуляторного центра головного мозга; одышка (более 60 дыханий в мин.), наблюдалось как в первые минуты рождения, так и в первые часы. В клинической картине отмечалось гипоксемия, снижение $\mathrm{PaO} 2$ крови $<40$ мм рт.ст., вторичное апноэ; почти у всех детей наблюдалось западение грудной клетки, у некоторых - мечевидного отростка; отмечался периоральный и акроцианозы при уровне снижение $\mathrm{PaO} 2$ крови до 30 мм рт.ст. Аускультативно в легких выслушивалось ослабленное дыхание, крепитирующие хрипы, которые на фоне ИВЛ приобретали вид обычных нормальных дыхательных шумов. RH-от небольшого уменьшения пневматизации до "белых легких" (рис. 3). Проводимая нами интенсивная терапия включала респираторную поддержку (СРАР, механическую вентиляцию, сурфактантотерапию), рациональную антибиотикотерапию, симптоматическую терапию. В качестве сурфактантной терапии нами применен куросурф из расчета 200 мг/кг массы тела. При среднетяжелом течении РДС (оценка 4-6 баллов) недоношенным детям проводили вентиляцию в режиме СРАР через интраназальные канюли или через эндотрахеальную трубку.

При тяжелом течении РДС (оценка более 6 баллов) проводили ИВЛ. Безусловно, в раннем неонатальном периоде, существует вероятность развития отдалённых последствий проведения ИВЛ. Согласно нашему мнению, для снижения количества осложнений необходимо оптимизировать стратегию проведения ИВЛ у недоношенных детей с РДС. В настоящее время существуют различные направления оптимизации, начиная от взвешенного подбора параметров вентиляции и заканчивая предоставлением большей свободы младенцу при проведении ИВЛ. Подобная тактика привела к сокращению 


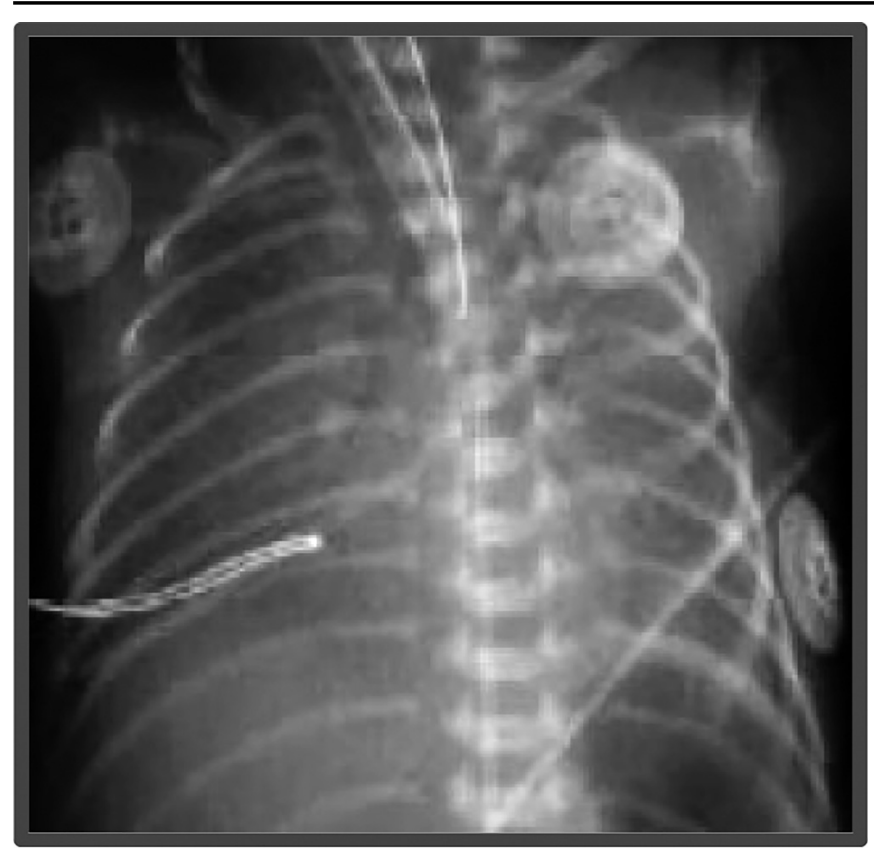

Рис. 3. РДС. Интенсивное затемнение легочных полей - симптом "матового стекла". Визуализируются линейные просветления, обусловленные заполненными воздухом бронхами - "воздушная бронхограмма".

сроков нахождения детей в отделении реанимации. Во всех случаях, когда младенец находился не в критическом состоянии, то есть не наблюдались признаки дыхательной и сердечно-сосудистой декомпенсации, начинали с режимов вспомогательной синхронизированной (триггерной) вентиляции. Данный подход обусловлен тем, что позволяет младенцу активно участвовать в поддержании необходимого объема минутной вентиляции легких, в итоге, уменьшаются сроки проведения ИВЛ и частоты развития осложнений. Вместе с тем, выбор конкретного режима зависел от выраженности дыхательных усилий ребенка и возможностей используемого аппарата ИВЛ. Изначально нами проводилась установка первоначальных параметров: чувствительность триггера по потоку (устанавливалась на самый возможно низкий уровень), который позволял, с одной стороны уловить сенсору снижение потока в дыхательном контуре при самостоятельном вдохе младенца, а с другой избежать аутотриггирования. Правильность своего выбора проверяли по волне потока и визуального наблюдения за младенцем. Поддержку давлением изначально выставляли равный базовому: PS=PIP-PEEP, но не менее 6-8 см вод. ст.; время вдоха 0,28 сек 0,38 сек; основной поток у недоношенных 8-10 л/мин; время повышения давления устанавливали от 1 - (наиболее быстрое) до 7 - (наиболее медленное). Необходимо отметить, что лучше выбрать значения 4-6, что снизит риск баротравмы; далее нами выбиралось значение завершения вдоха 5-10\%. Важно подчеркнуть, что данный параметр трудно подбираем у недоношенных детей, так как при значениях 15\%; 25\% увеличивается риск формирования "воздушных ловушек". Остальные параметры оставлялись прежними до получения первого результата газового состава крови и RH грудной клетки. Применяемая нами тактика респираторной поддержки недоношенным детям заключалась в выборе конкретного режима, в зависимости от степени тяжести РДС. При среднетяжелом течении РДС проводили вентиляцию в режиме СРАР. При тяжелом РДС проводили ИВЛ. На СРАР-е 27 (26,5\%), на ИВЛ 17 (16,7\%) случаев соответственно. Если ребенок находился не в критическом состоянии, начинали с режимов триггерной вентиляции. Изначально проводилась установка первоначальных параметров. Правильность выбора проверялось по волне потока и визуального наблюдения за ребёнком. Было установлено, что применение режима PSV у детей с РДС при переходе от контролируемой к вспомогательной вентиляции позволяет поддерживать адекватную альвеолярную вентиляцию при более низких значениях PIP, PEEP, Tin, МАР, что снижает инвазивность респираторной поддержки. Необходимо отметить, каждый раз при подборе параметров механической вентиляции легких проверяли КОС, если параметр не изменялся, то в этих случаях КОС проверяли 4 раза в сутки. При механической вентиляции одновременно изменять несколько параметров не рекомендуется. При необходимости, для изменения параметров ИВЛ, мы применяли следующий алгоритм: управление параметрами, основанных на значениях $\mathrm{PaC02}$ меньше 35 мм рт.ст. - снижали количество аппаратных вдохов на 5 циклов; если меньше 30 мм рт.ст. - снижали количество аппаратных вдохов на 10 циклов; если 40-50 мм рт.ст. - не изменяли количество аппаратных вдохов, если нет необходимости; 
если больше 50 мм рт.ст. - увеличивали количество аппаратных вдохов на 5 циклов и повторяли определение КОС через 45 минут. Параметры, основанные на RH легких: правый купол диафрагмы на уровне 8-9 ребра - оптимальный показатель; выше 7 ребра, увеличивали PIP на 5 см $\mathrm{H}_{2} \mathrm{O}$; если ниже 10 ребра, снижали PIP на 5 см $\mathrm{H}_{2} \mathrm{O}$. При подготовке к экстубации снижали количество аппаратных вдохов до 0 в 1 мин. Концентрацию $\mathrm{O}_{2}$ во вдыхаемой смеси менее $30 \%$, уровень поддержки давлением до 8-10 cм вод. ст. Экстубация возможна, если младенец находится на полном PSV 24 часа, при этом значения КОС в норме, общая ЧД не более 80 в 1 мин., микроциркуляция удовлетворительная, при аускультации легких дыхание проводится равномерно, на RH грудной клетки нет участков ателектазов и гиповентиляции. Мы не использовали транквилизаторы и анальгетики для синхронизации при проведении ИВЛ в режиме PSV. Таким образом, подводя итог, необходимо отметить: 1) применение режима PSV у недоношенных детей с РДС позволяет поддерживать адекватную альвеолярную вентиляцию при более низких значениях PIP, PEEP, Tin, MAP; 2) применение триггерной вентиляции способствует снижению количества осложнений интенсивной терапии; 3) перевод на триггерный режим вентиляции сокращает сроки использования гипероксической газовой смеси; 4) своевременно начатая и адекватно проводимая респираторная поддержка при РДС способствует улучшению клинического неврологического фона, снижению последствий ГИЭ, что позволит предотвратить неонатальную заболеваемость, инвалидность и летальность.

У всех недоношенных детей данной категории наблюдалось перинатальное гипоксическое-ишемическое поражение ЦНС с различными синдромами и симптомами, несущие определенную степень тяжести течения. Внутриутробная гипоксия зарегистрирована у 68 (66,7\%) младенцев, у 34 (33,3\%) детей родились в асфиксии различной степени тяжести, имело место и обвитие пуповины вокруг шеи. ПП ЦНС гипоксическиишемического характера зависела от тяжести перенесенной гипоксии, от выраженности церебральной ишемии (ЦИ) мозга,от степени зрелости ребенка. Легкая І степень ЦИ отмечена в 51 (50\%), среднетяжелая II ст. - 32 (31,4\%); тяжелая III-я ст. - 19 (18,6\%) случаев соответственно. Проведенные наблюдения показали, что у недоношенных детей гипоксическое поражение (ГП) ЦНС клинически протекала с различной степенью тяжести, характеризовалась волнообразностью и стадийностью течения. В частности, клиническая картина острого периода имела стертое течение. На наш взгляд, объяснением послужило тяжесть общего состояния младенца, зависимое как от степени морфофункциональной незрелости, так и наличием фона, таких как РДС, протекающей с различной степенью тяжести, ЗВУР, дыхательная недостаточность и т.д., которые выступали на первом плане. Согласно классификации Sarnat H.B. у недоношенных детей при легкой степени ГП нервной системы наблюдались гипертензионный синдром, носящий незначительный характер, синдром угнетения, гипоксемия, гиперкапния умеренной степени выраженности, ацидоз. Допплерографические исследования при этом выявили повышение скорости кровотока по магистральным сосудам мозга компенсаторного характера. При средней степени тяжести течения ГП мозга, у детей данной категории зарегистрированы симптомы повышения внутричерепного давления, судороги, артериальное давление носила нестабильный характер, наблюдались гипертензии, апноэ. Синдромы угнетения ЦНС проявлялись на протяжении $8 \pm 2$ суток и более, в зависимости от степени незрелости младенца. Допплерографические исследования показали повышение диастолической скорости, признаки гипоперфузии в передней мозговой артерии, снижение индекса резизтентности.

При тяжелом течении ГП ЦНС (III степень ЦИ) у данных детей отмечались судороги, синдром угнетения, нарушение ритма дыхания, глазная неврологическая симптоматика, отек мозга. Наблюдалась выраженность метаболического ацидоза, наиболее высоко зарегистрированная у детей с III-ей степенью ЦИ $33,3 \%$ при $\mathrm{pH} 7,2 \pm 0,1$, по отношению к мла-

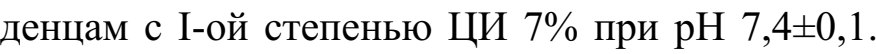
У детей, родившихся в асфиксии, церебральные нарушения коррегировали с тяжестью течения асфиксии. 
Младенцы с III-ей степенью ЦИ чаще имели ЗВУР. У недоношенных детей приступы апноэ протекали с брадикардией, наблюдались малоподвижность, срыгивания, местами рвота, отсутствие сосания, ослабление или угнетение рефлексов, как орального автоматизма, так и врожденного автоматизма. Допплерографические исследования при тяжелой степени ГИЭ выявили стойкую церебральную гипоперфузию, снижение диастолической скорости, увеличение индекса резистентности. Частой и серьезной проблемой для недоношенных младенцев являются гипоксически-геморрагические поражения ЦНС, проявляющиеся ВЧК различной степени тяжести. Отмечены ПВК и ВЖК. У младенцев с гестационным возрастом 30 недель составила - 3 (2,9\%); 28-29 недель - 5 (4,9\%); 26-27 недель - 6 (5,9\%); 24-25 недель - 7 (6,8\%) соответственно. ПВК с субэпидемальным кровоизлиянием I ст. имело место в $9(8,8 \%)$ случаев; ПВК II ст. - 5 (4,9\%); ПВК III ст. $-3(2,9 \%)$ соответственно (рис. 4 и 5). Необходимо отметить, что у недоношенных детей клинически ВЧК характеризовалась малой симптоматикой.

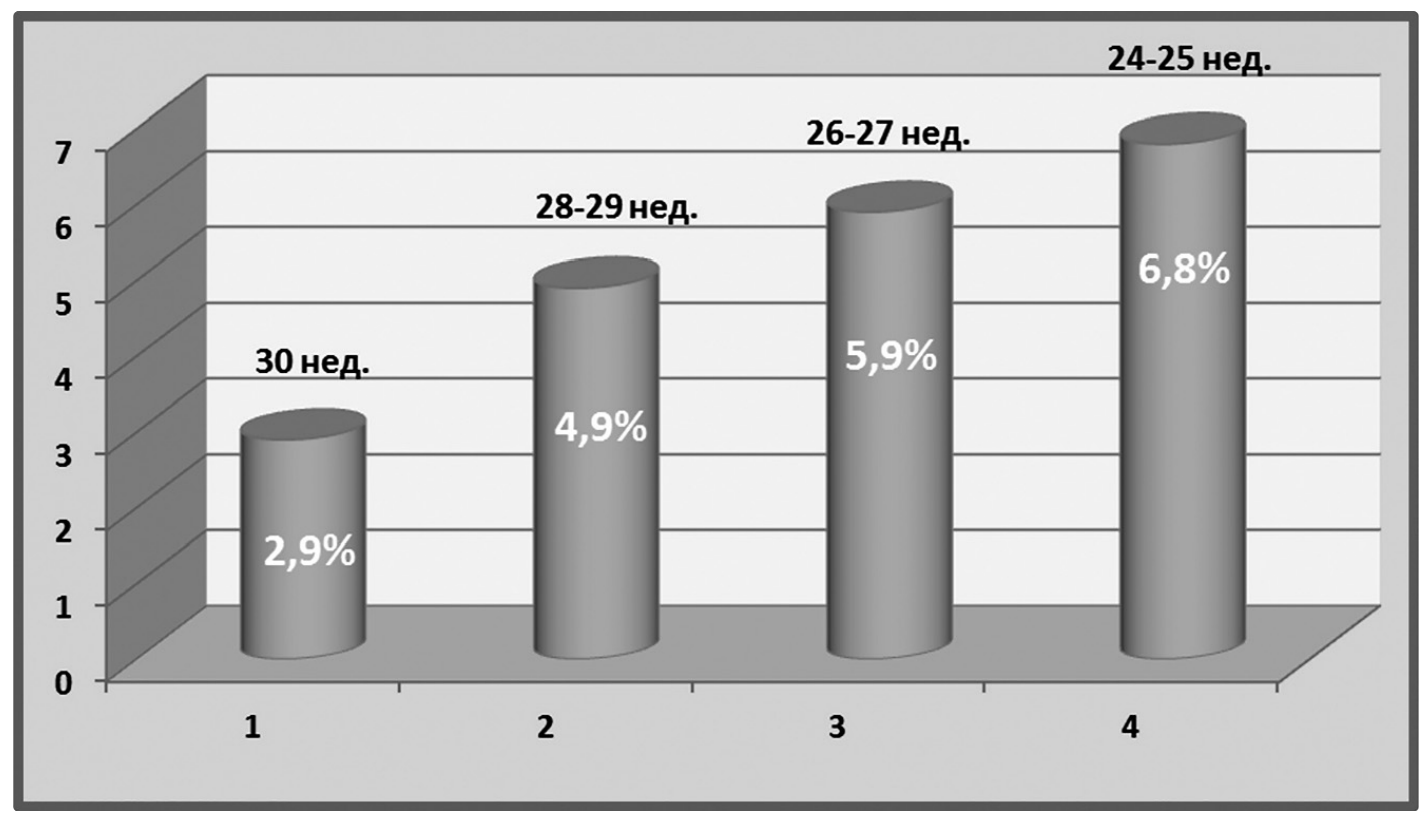

Рис. 4. Диаграмма частоты встречаемости ВЧК у недоношенных детей.

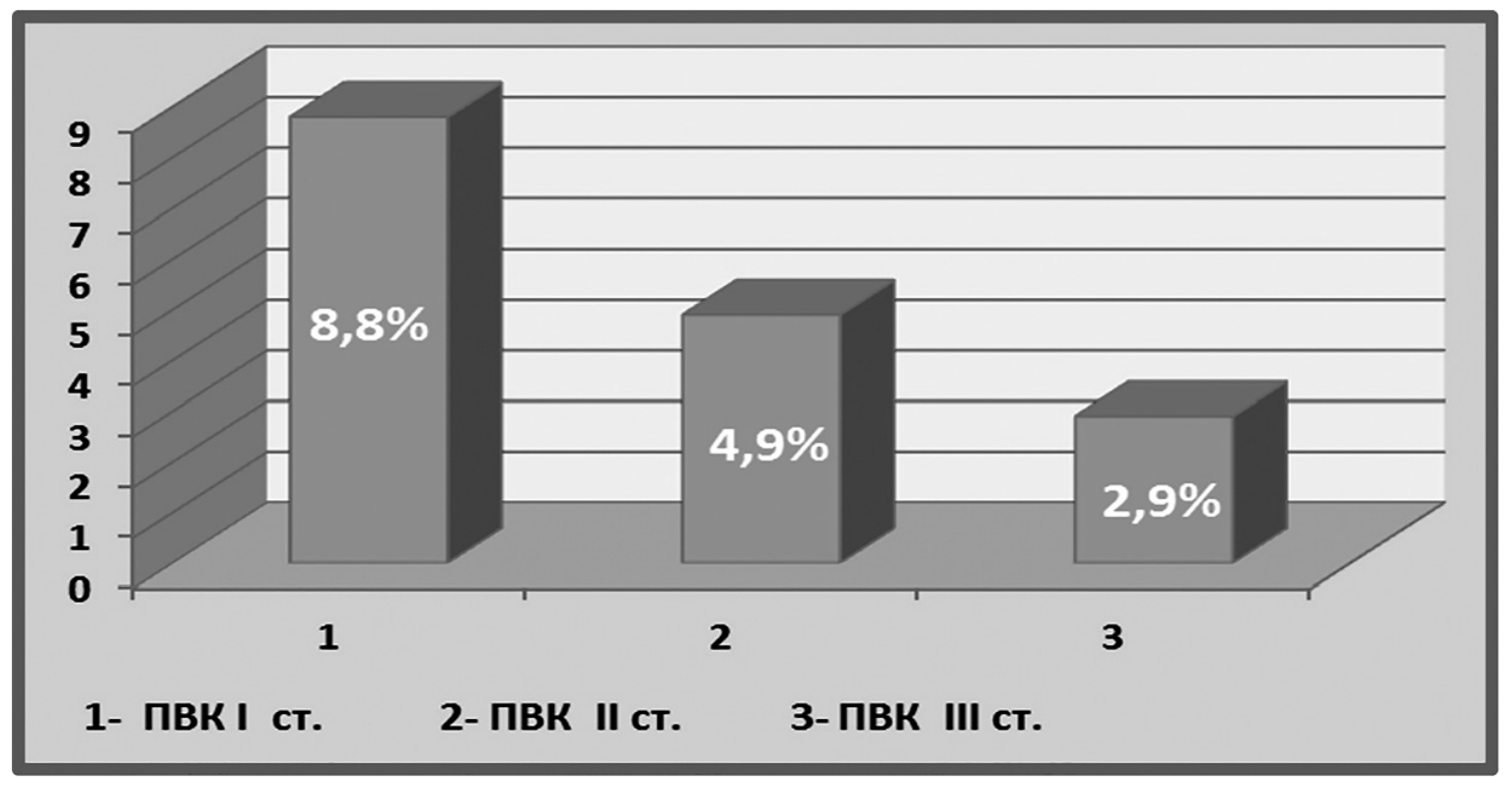

Рис. 5. Диаграмма частоты встречаемости ПВК у недоношенных детей. 
В клинической картине наблюдались слабый, монотонный крик, гипотонус мышц, снижение двигательной активности, наличие глазной неврологической симптоматики: устремленный взгляд, горизонтальный нистагм, признаки внутричерепной гипертензии, тонические позы, судороги, расстройства дыхания.

Чем меньше гестационный возраст ребенка, тем более выраженное течение ГИЭ. Наблюдаемые вышеперечисленные неврологические симптомы сопровождались изменениями лабораторных показателей, в частности: ацидоз, носящий как респираторный, так и метаболический характер, гипоксемия, анемия геморрагического характера и т.д. На рис. 6-8 показаны НСГ картина поражения ЦНС у недоношенных младенцев. У 2-х недоношенных детей ВЖК имела исход в приобретенную гидроцефалию, которая клинически характеризовалась гипер- тензией, общим беспокойством, запрокидыванием головы, монотонным плачем, выбуханием и напряженностью большого родничка, расхождением саггитального шва на 0,5 cм. Со стороны глазной неврологической симптоматики отмечались: симптом "Грефе", на глазном дне визуализировались застойные изменения, наблюдались тремор кистей рук, в кистях и стопах - гипертонус. Необходимо отметить, что у недоношенных младенцев специфической клинической симптоматики при ПВЛ не наблюдалось. Отмечались: адинамия, гипотония, вялость, слабый, писклявый крик, судороги, гипорефлексия, отсутствие сосательногого и глотательных рефлексов, цианозы (периоральный, акроцианоз). На НСГ у $4,9 \%$ визуализировались повышение эхогенной плотности в перивентрикулярных зонах; расширение желудочков, сморщивание белого вещества вокруг желудочков.

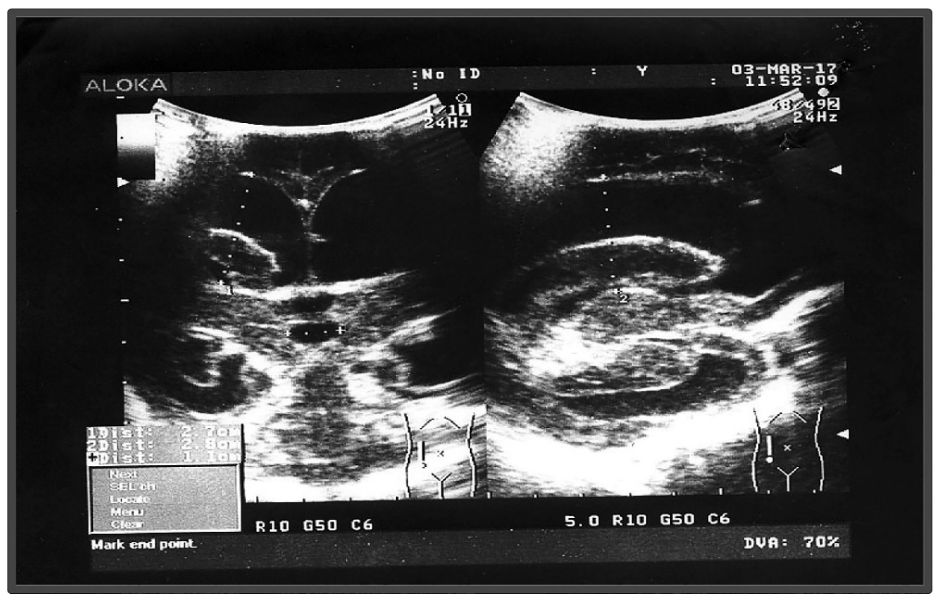

Рис. 6. НСГ. Дилатация боковых желудочков тяжелой степени. Окклюзионная гидроцефалия (прогрессирующая). Недоношенный I ст. (собственное наблюдение).

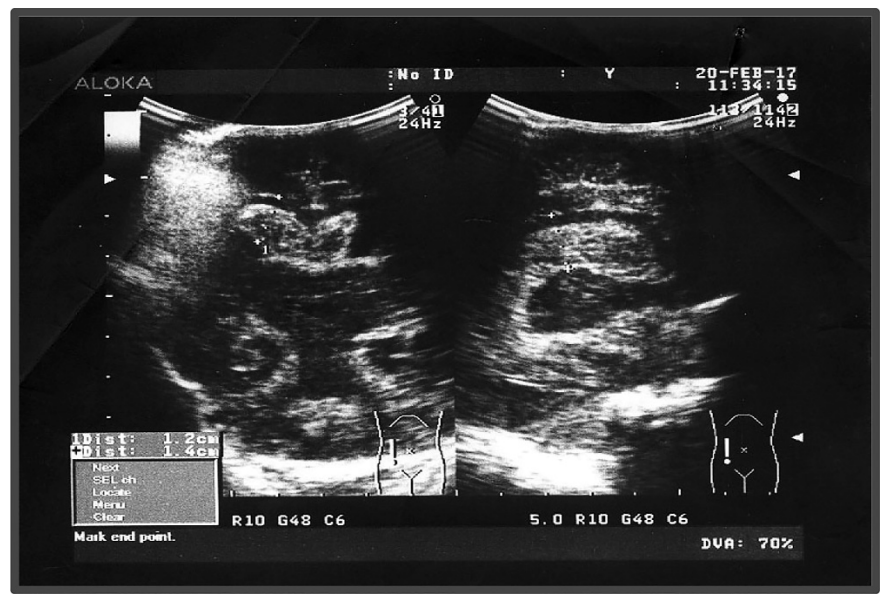

Рис. 7. НСГ. Дилатация боковых и IV-го желудочков средней тяжести. ВЧК III ст. (стадия рассасывания) (собственное наблюдение). 


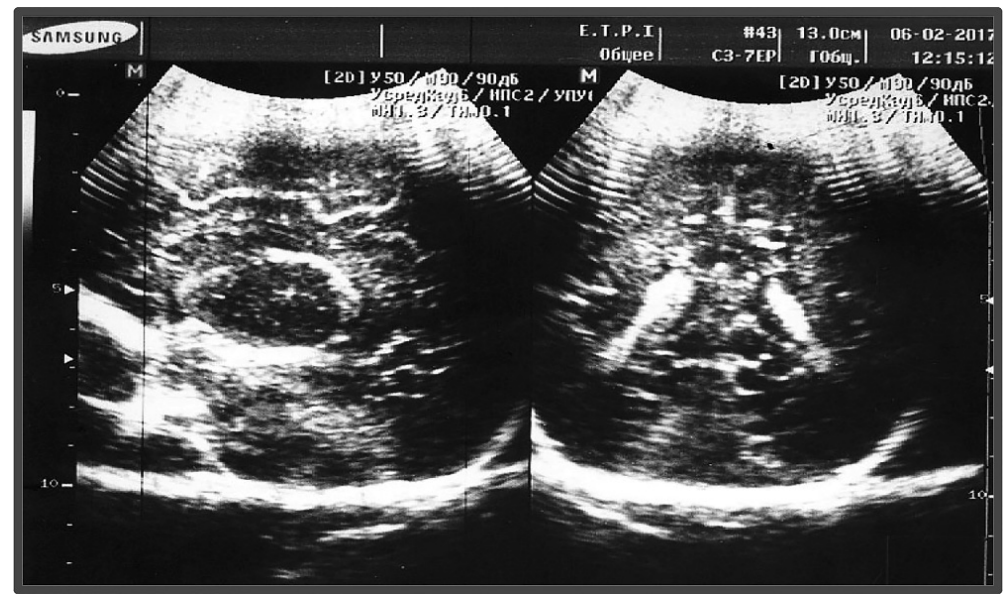

Рис. 8. НСГ Гипоксически-ишемическая энцефалопатия. Недоношенный II ст. (собственное наблюдение).

Судороги у недоношенных детей наблюдались в горизонтальном направлении нистагмоидные подергивания глазных яблок, мигательные движения, гримасы, фиксация взора, небольшие подергивание со стороны рта, верхних и нижних конечностей, вздрагиваний, местами регистрировались приступы судорожного апноэ. Клонические судороги чаще наблюдались у недоношенных детей 34-36 недель гестационного возраста. Тонического характера судороги имели место у 11,2\% недоношенных детей. Судороги в основном наблюдались на первой неделе жизни младенцев. Показательна была и весовая динамика у наблюдаемых младенцев. Для этих детей была характерна первоначальная потеря веса на $10-15 \%$ на $6 \pm 1$ сутки. Необходимо подчеркнуть, что потеря веса зависела от тяжести состояния ребенка. Вес изменялся с наличием отеков $(8,6 \%)$, либо типа склередемы, либо гипостатических. Согласно оценке со стороны антропометрических показателей по шкалам Dubowits L., Дементьевой Г.M., Коротковой Е.В. и по оценке параметров морфофункциональной незрелости по шкале Hoepffnes W., Rauntenbach M.., наблюдалось отставание в развития по гестационному сроку.

Гемодинамические расстройства у данной категории младенцев проявлялись нарушением микроциркуляции, периферическим и центральным цианозами, нарушением ритма сердечной деятельности, отечным синдромом, мраморностью кожных покровов, длительностью "белого пятна" более 3-х секунд. Гемодинами- ческие расстройства у всех недоношенных детей расценены как вторичные, обусловленные поражением легких и ЦНС.

Со стороны гепатобилиарной системы отмечены: конъюгационная желтуха в 36 (35,2\%) случаев; появившаяся на 2-3-и сутки жизни, исчезала в течение 12-14 дней, у некоторых младенцев имела затяжной характер 19 (18,6\%), что изъясняется морфофункциональной незрелостью гепатобилиарной системы. Диспептический синдром, в виде метиоризма, неустойчивого стула наблюдалось в 18 (17,6\%) случаев; рвота отмечена в $12(11,8 \%)$ случаев соответственно.

Заключение. Таким образом, как показали наши исследования, наиболее сильно страдает мозг и легкие, что способствует развитию неврологических и соматических расстройств. Полученные результаты в ходе проведенных исследований, свидетельствуют о стойких нарушениях, как со стороны ЦНС, таких как ДЦП, ГИЭ, синдром вегето-висцеральных нарушений, отек мозга, судорожный, гидроцефальный синдромы, ВЧК в основном ПВК, ПВЛ, так и со стороны других органов и систем. Сравнительный анализ клинико-лабораторно-диагностической картины у данной категории детей показал, что клиническое течение ГИЭ находится в прямой зависимости от состояния здоровья и наличия отягощенных факторов акушерского и гинекологического статуса матерей, фетоплацентарного фона, от гестационного возраста и тяжести перенесенной перинатальной гипоксии (как 
внутриутробно, так и в родах). Важно отметить, что наиболее тяжелое течение ГИЭ отмечены у детей с ЭНМТ и НМТ, что изъясняется как структурной, так морфофункциональной незрелостью их мозга. Анатомо-физиологические

\section{ЛИТЕРАТУРА - ӘDӘВIYYAT - REFERENCES}

1. Haciyeva N.N. Mərkəzi sinir sisteminin perinatal hipoksikişemik, travmatik zədələnməsi olan yenidoğulanlarda ağrı sindromu və ağrısızlaşdırma yolları. Tibb üzrə fəls. dok. dis. avtoreferat1. Bak1. 2009, 21 soh.

2. Qurbanova G.M. Bətndaxili herpesvirus infeksiyalarının vaxtından qabaq doğulan uşaqlarda serebral pozğunluqların formalaşmasına təsiri. Tibb üzrə fəls. dok. dis. avtoreferatı. Bak1, 2014, 22 səh.

3. Muxtarova S.N. Mərkəzi sinir sisteminin perinatal hipoksik zədələnməsi olan yenidoğulanlarda hematoensefalik baryerin funksiya pozulmalarının klinik-immunkimyəvi meyarları və onun korreksiyası. Tibb üzrə fəls. dok. dis. avtoreferatı. Bak1. 2009, 22 səh.

4. Orucova P.Ө. Yenidoğulanlarda mərkəzi sinir sisteminin perinatal hipoksik zədələnmələri zamanı adheziya molekullarının klinik əhəmiyyəti. Tibb üzrə fəls. dok. dis. avtoreferatı. 2016, Bak1, 22 səh.

5. Али-заде С.Ф. Поражения ЦНС при цитомегаловирусной инфекции у новорожденных детей / Материалы научной конференции, посвященной юбилею 75-летия проф. Т.Г. Кадыровой. Баку, 2003, с.48-50

6. Али-заде С.Ф. Гасанов Р.Л., Мамедбейли А. Клинические особенности поражения ЦНС при цитомегаловирусной инфекции у новорожденных детей // Азербайджанский медицинский журнал, 2008, №1 с.65-68

7. Мамедбейли А.К. Сравнительная характеристика поражений центральной нервной системы у новорожденных детей с внутриутробными инфекциями различной этиологии. Автореф. дисс.. ... на соиск. уч.ст. к.м.н., Баку, 2009, $21 \mathrm{c}$.

8. Альперина О.Н. Клинические особенности и методы патогенетической коррекции перинатального поражения центральной нервной системы у недоношенных детей с ретинопатией. Автореф. дисс. ... на соиск. уч. ст. к.м.н. 2011, Екатеринбург, 21 с.

9. Барашнев Ю.И. Перинатальная неврология. Москва: Триада-Х, 2001, 640 с

10. Бочарова Б.А., Корытова Н.Г., Труцфанова Л.В. и др. Проблемы ранней диагностики и профилактики отдаленных последствий перинатального центральной нервной системы // Российский педиатрический журнал, 2003, №3, особенности недоношенных детей, наличие анте-, интра- и постнатальных факторов способствуют развитию ГИЭ, что требует поиска новых подходов в клинико-диагностической и лечебно-профилактических сферах.

c. $52-54$

11. Желев В.А. Механизмы клинико-метаболической адаптации глубоконедоношенных новорожденных с гипоксическим поражением центральной нервной системы на этапах реабилитации. Автореф. дисс. ... на соиск. уч.ст. д.м.н., 2005, Томск, 32 с.

12. Ковальчук-Ковалевская О.В. Особенности формирования функций ЦНС у новорожденных детей с задержкой внутриутробного развития. Автореф. дисс. ... на соиск. уч. ст. к.м.н., 2005, Санкт-Петербург, 22 с.

13. Михалев Е.В. Клинико-патогенетические аспекты гнойного менингита у недоношенных новорожденных с гипоксическим поражением центральной нервной системы. Автореф. дисс. ... на соиск. уч. ст. д.м.н., 2005, Томск, $32 \mathrm{c}$.

14. Пальчик А.Б. Лекция по неврологии развития. Москва: МЕДпресс-информ, 2012, 368 с.

15. Пальчик А.Б., Федорова Л.А., Понятишин А.Е. Неврология недоношенных детей. Москва: МЕДпрессинформ, 2011, 352 с.

16. Althabe F., Belizan J.M., McClure E.M., Hemingway Foday J. et al. A population-based, multifaceted strategy to implement antenatal corticosteroid treatment versus standard care for the reduction of neonatal mortality due to preterm birth in low-income and middle-income countries: the ACT cluster-randomised trial // J. Lancet. 2015; vol.385(9968), p.629-639

17. Conde-Agudelo A., Diaz-Rossello J.L. Kangaroo mother care to reduce morbidity and mortality in low birthweight infants // Cochrane Database Syst. Rev. 2014, vol. 4, CD002771

18. Goldenberg R.L., Culhane J.F, Iams J.D, Romero R. Epidemiology and causes of preterm birth // The Lancet, 2008, vol.371, № 9606, p. 75-84

19. Kinney M.V., Lawn J.E., Howson C.P. et al. 15 Million preterm births annually: what has changed this year? // J. Reprod. Health. 2012, vol. 9, p.28

20. Wong L.F., Wilkes J., Korgenski K., Varner M.W. et al. Risk factors associated with preterm birth after a prior term delivery // BJOG. 2015 DOI: 10.1111/1471-0528.13683 


\title{
XÜLASə
}

\section{VAXTINDAN ӘVVӘL DOĞULMUŞ UŞAQLARDA MəRKəZI SINIIR SISTEMININ PATOLOGIYASININ KLİNIK Və DİAQNOSTIK XARAKTERISTIKASI}

\author{
Osədova T.A. \\ Ә.Oliyev adına Azarbaycan Dövlat Həkimlari Təkmillaşdirmə İnstitutu, \\ pediatriya kafedrası, Bakl, Azorbaycan
}

Məqalədə gestasiya yaşından asılı olaraq vaxtından əvvəl doğulmuş körpələrdə hipoksik-işemik ensefalopatiyanın (HIE) klinik xüsusiyyətləri verimişdir. Göstərilmişdir ki, vaxtından əvvəl doğulmuş körpələr ən çox beyin və ağciyərlər patologiyayasına məruz qalırlar, bu da nevroloji və somatik pozğunluqların inkişafina səbəb olur. Aparılan tədqiqatlar göstərir ki, vaxtından əvvəl doğulmuş körpələrdə HIE-nin klinik gedişi əsasən anaların sağlamlığının vəziyyətindən, fetoplacental fondan, körpənin beyninin struktur və morfofunksional yetişməzliyindən, ante, intra- və postnatal amillərin mövcudluğundan birbaşa asılıdır. Uşağın gestasiya yaşı nə qədər aşağıdırsa, bir o qədər mərkəzi sinir sisteminin fəsadlarının daha ağır keçməsi mövcuddur. HIE-nin ən ağır klinik gedişi ekstremal az çəkili (EAÇ) və az çəkili (AÇ) körpələrdə müşahidə edilmişdir.

Açar sözlər: vaxtından əvvəl doğulmuş uşaqlar, mərkəzi sinir sisteminin patologiyası, perinatal hipoksik ensefalopatiya.

\section{SUMMARY}

\section{CLINICAL AND DIAGNOSTIC CHARACTERISTICS OF PREMATURE INFANTS WITH LESION CENTRAL NERVOUS SYSTEM}

\author{
Asadova T.A. \\ Azerbaijan State Advanced Training Institute for Doctors named after A. Aliyev, \\ department of pediatrics, Baku, Azerbaijan
}

This article shows clinical features of the course of hypoxic-ischemic encephalopathy (HIE) in premature infants depending on gestation age. It has been shown that the brain and lungs suffer the most, which contributes to the development of neurological and somatic disorders. Studies have shown that the clinical course of HIE in premature infants is directly dependent on the state of health of mothers, fetoplacental background, on the structural and functional immaturity of the brain of infants, the presence of ante-, intra- and postnatal factors. The smaller the gestational age of the child, the more severe the long-term consequences from the central nervous system. The most severe course of HIE was observed in children with extremely low birth weight (ELBW) and low birth weight of (LBW).

Keywords: prematurity, central nervous system pathology, perinatal hypoxic encephalpathy.

Redaksiyaya daxil olub: 25.08 .2020

Çapa tövsiya olunub: 14.09 .2020

Rayçi: professor A.İ.Hasanov 